\title{
Effect of the Addition of Essential Oils and Functional Extracts of Clove on Physicochemical Properties of Chitosan-Based Films
}

\author{
Paola Reyes-Chaparro, Nestor Gutierrez-Mendez, Erika Salas-Muñoz, \\ Juan Guillermo Ayala-Soto, David Chavez-Flores, and León Hernández-Ochoa
}

Facultad de Ciencias Químicas, Universidad Autónoma de Chihuahua, Campus Universitario No. 2, Apartado Postal 669, 31125 Chihuahua, CHIH, Mexico

Correspondence should be addressed to León Hernández-Ochoa; lhernandez@uach.mx

Received 10 February 2015; Revised 6 May 2015; Accepted 18 June 2015

Academic Editor: Xingxun Liu

Copyright (C) 2015 Paola Reyes-Chaparro et al. This is an open access article distributed under the Creative Commons Attribution License, which permits unrestricted use, distribution, and reproduction in any medium, provided the original work is properly cited.

\begin{abstract}
Mechanical and barrier properties of chitosan films prepared with essential oils of clove and functional extract were studied. The films made with functional extracts (esters $\mathrm{E}_{6}$ and $\mathrm{E}_{7}$ ) presented the significant increment of extensibility compared with the untreated chitosan films. In the case of punction test, the films made with the esters $\mathrm{E}_{6}$ and $\mathrm{E}_{7}$ resisted more the applied strength before tearing up compared with the chitosan control film (without any treatment). Thermogravimetric analysis values were determined for the chitosan control film and chitosan film treated with clove essential oil obtaining $112.17^{\circ} \mathrm{C}$ and $176.73^{\circ} \mathrm{C}$, respectively. Atomic force microscopy (AFM) was used to determine their morphology by analyzing their surfaces and phase arrangement; AFM was also used to observe the porosity in chitosan-based antimicrobial films and the chitosan films incorporating functional extracts. The water vapour permeability (WVP) data showed that incorporating the functional extract to the formulation of films has a positive effect on water vapour barrier properties. In general, the incorporation of essential oils and functional extract of clove at $20 \%$ in chitosan films caused microstructural changes that were dependent on the different affinity of components.
\end{abstract}

\section{Introduction}

Polymers derived from renewable resources are now considered promising alternatives to traditional petropolymers as they mitigate current environmental concern (raw renewable materials/biodegradability) [1]. Chitin is the most important component of the exoskeleton of invertebrates, molluscs, and lower forms of vegetal life (fungus and mold). It is nature's second most abundant polysaccharide after cellulose; their chemical formula is similar, but chitin has an acetamide instead of the hydroxyl group of $\mathrm{C}_{2}[2,3]$. Chitin is not present as a natural chemical entity, but it is considered the product of the separation of several constituents; it is bound to proteins, minerals, and pigments in a complex matrix named chitinase structure. It is a linear polymer with a predominance of residues of 2-acetamido-2-deoxy-D-glucopyranose (Nacetyl-D-glucosamine) and in a lower proportion 2-amine2 -deoxy- $\beta$-D-glucopyranose (D-glucosamine) [3]. Once it is isolated, it presents a colorless, crystalline dust (insoluble in water, organic solvents, acids, and alkalis diluted and concentrated). Its low solubility is due to the formation of intermolecular hydrogen bonds between the chains $\beta$-(1-4)glycoside and to its rigid crystalline structure $[4,5]$. Chitin's main derivate is chitosan, which is produced by alkaline or enzymatic deacetylation or chitin. This biopolymer contains a higher proportion of $\mathrm{D}$-glucosamine groups than $\mathrm{N}$-acetylD-glucosamine. Thereby, chitosan dissolves at low concentrations of aqueous solutions of organic acids, for instance, acetic and formic acids, and inorganic acids, yielding in all cases viscose solutions. This is due to the fact that the amine group is totally protonated at $\mathrm{pH}$ 3.0. Complete deacetylation is hardly achieved and normally unnecessary since the solubility in diluted acids is reached starting with $60 \%$ degree of deacetylation. Chitosan is a linear polyaminosaccharide of high molecular weight, and its derivates are used in a wide variety of applications, for instance, alternative materials of biodegradable and antimicrobial flexible films, the latter due to its capacity of absorbing nutrients used by bacteria and 
the capacity to bond water and inhibit the enzymatic system [6]. These materials' efficiency depends on their molecular weight and their degree of deacetylation $[7,8]$. Some authors [7-9] mention that chitosan has antimicrobial activity against certain bacteria, molds, and yeasts (except Zigomycetes which have chitosan as main component in its cell wall). On the other hand, the medium conditions such as $\mathrm{pH}$, temperature, and food composition are factors that have influence over the antimicrobial capacity. An important application of chitosan is the elaboration of antimicrobial films that can be used to extend fruit, vegetable, and sea or meat products' shelf life, reducing dehydration, oxidative rancidity, and superficial darkening [1,9-11]. Chitosan has a potential interest as a base for films because it has oxygen-blocking properties. However, chitosan is a hydrophilic molecule that should be treated with some additives to provoke certain hydrophobicity and to improve its mechanical properties $[1,10,11]$. Nevertheless, pure chitosan films are fragile and need plasticizer to reduce frictional forces between the polymer chains, as hydrogen bonds or ionic forces, thus improving mechanical properties [12].

The replacement of synthetic products with more natural alternatives is safer when the new product is as effective as the product previously used [13]. The essential oils obtained from spices are among these alternatives, as their active components (including terpenes, aldehydes, acids, alcohols, phenols, esters, and ketones) for their antimicrobial activity [14], and have been recently added to food packing materials [8]. The most common method of essential oils extraction is by hydrodistillation, although the use of petroleum-derived solvents is also used to purify plant-derived compounds. However, the latter method can be dangerous because of the use of explosive and toxic solvents [14]. An option would be the use of alternative solvents, also known as green solvents because they are not derived from petroleum products; therefore, they are not as detrimental to the environment. Among those alternative solvents, fatty acid ethyl esters are extracted from plants, are becoming an important option because of their amphipathic property and biodegradability, and are also nontoxic and nonirritable [15]. Thus, the aim of this work is focused on analyzing the effect of the incorporation of essential oil and functional extract of clove on functional properties of chitosan-based films for food packaging applications.

\section{Material and Methods}

2.1. Materials. Clove (Eugenia caryophyllata) was given by Comercial Cordona from Chihuahua, Mexico. Chitosan (low molecular weight, 75-85\% deacetylated CAS 9012-76-4), ethyl caproate (99\% CAS. 123-60-0), ethyl heptanoate (99\%, CAS 106-30-9), ethyl caprylate (99\% CAS. 106-32-1), ethyl nonanoate (97\% CAS. 123-29-5), acetic acid (99\% CAS 64-197 ), and glycerin (99\% CAS 56-81-5) were provided by SigmaAldrich.

2.1.1. Essential Oil (EO) and Functional Extracts (EX). Plant material (clove) was subjected to distillation process using a Schilcher device. For hydrodistillation process, plant material was immersed in water and for cohydrodistillation process, fatty acid ethyl esters were added as cosolvents of extraction. The ester used was ethyl heptanoate $\left(E_{7}\right)$; operation conditions depended on the vegetal material used, according to Hernández-Ochoa et al. [15]. $200 \mathrm{~g}$ of the clove was added to $4 \mathrm{~L}$ of water and $20 \mathrm{~mL}$ of ethyl ester. The homogeneous mixture composed of oil and ester was called functional extracts (EX).

2.1.2. Chitosan-Based Films Elaboration. The antimicrobial films were prepared according to Ouattar et al. [16]. The films were prepared by dissolving low molecular weight chitosan in acetic acid aqueous solution $(1 \% \mathrm{v} / \mathrm{v})$, to obtain a final concentration of $2 \%(\mathrm{w} / \mathrm{v})$. Glycerin $2 \%(\mathrm{w} / \mathrm{v})$ was added as plasticizer; essential oils and functional extract of clove were also added to the film's mixture. An immersion mixer (Bamix) was used to homogenize all components, and $20 \mathrm{~mL}$ of the mixture was poured into glass Petri dishes $(15 \times 90 \mathrm{~mm})$ and placed in a convection oven (Fisher Scientific) $\left(60^{\circ} \mathrm{C}, 4 \mathrm{~h}\right)$ to form the antimicrobial films.

2.1.3. Tensile Properties. A texturometer (TA XT plus) with a $0.049-\mathrm{N}$ load cell was used. In the puncture test, a bradawl $\mathrm{P} / 2 \mathrm{~N}$ with a $2.38 \mathrm{~mm}$ bit was used. The speed during the test was of $2 \mathrm{~mm} / \mathrm{s}$ and in the pretest was of $10 \mathrm{~mm} / \mathrm{s}$, with a route distance of $10 \mathrm{~mm} / \mathrm{s}$. The analysis was carried out in films of $9-\mathrm{cm}$ diameter and $0.054 \mathrm{~mm}$ thickness. The bradawl penetration was evaluated in five different parts of the films. The maximum strength was determined for each film formulation. For the extensibility test, a heavy duty platform (HDP)/Tortilla Pastry Burst rig device was used. The speed used in the extensibility test was of $2 \mathrm{~mm} / \mathrm{s}$. The analysis was carried out in $12-\mathrm{cm}$ diameter films according to Hernández-Ochoa et al. [15]. All determinations were performed in triplicate.

2.2. Thermogravimetric Analysis. Thermogravimetric analysis (TGA) test was carried out in a TGA-Q400 (TA Instruments, USA). Samples weighing around 5-10 mg were heated under dynamic mode. Measurements were performed at $10^{\circ} \mathrm{C} \mathrm{min}^{-1}$ from $30^{\circ} \mathrm{C}$ to $600^{\circ} \mathrm{C}$ under nitrogen atmosphere (low rate $50 \mathrm{~mL} \mathrm{~min}^{-1}$ ) in order to prevent any thermoxidative degradation.

2.3. Atomic Force Microscopy. The porosity of the antimicrobial films was evaluated using this technique. Multimode AFM with Nanoscope IV controller (Veeco Instruments, Santa Barbara, CA, USA) was used for both living cell imaging and force curves collection. This AFM was equipped with a Pico Force module. The Pico Force scanner had a maximum $X Y$ scan range of $50 \mu \mathrm{m} \times 50 \mu \mathrm{m}$ and $Z$ range of $20 \mu \mathrm{m}$. The sample was prepared taking a small section of the film and placing it in a cell, and the sample was set up in the microscope's sample holder. The upper side of the film was used in the test (in direct contact with a glass dish). A $125 \mu \mathrm{m}$ long cantilever was used at a resonance frequency of $250-300 \mathrm{KHz}$ and $294 \mathrm{KHz}$, with amplitude of 
1.35 V. The sample was analyzed using the contact mode technique that is based on the monitoring of the change of the cantilever's deflection through a photosensor and a laser beam. The cantilever oscillates at a frequency slightly under its resonance frequency $3-10 \%$, with amplitude in the 20 to $100 \mathrm{~nm}$ range. The images obtained were analyzed with the program WsXM 4.0 develop 11.4 determining the pore size, according to the technique described by Lavalle et al. [17].

2.4. Water Vapor Permeability Measurements. The water vapor permeability (WVP) of the films was determined at $25^{\circ} \mathrm{C}$ and $53-100 \mathrm{RH}$ gradients. The WVP was determined by making a modification of the ASTM-E96-95 gravimetric method for flexible films [18]. Three circular samples were cut $(3.5 \mathrm{~cm}$ in diameter) per formulation, selecting films without visible defects, such as cracks or visible pores. The thickness of each sample was determined in six random positions. Payne permeability cups of $3.5 \mathrm{~cm}$ in diameter were filled with $5 \mathrm{~mL}$ distilled water $(\mathrm{RH}=100 \%)$. Saturated solutions of magnesium nitrate were used to generate $53 \% \mathrm{RH}$ inside the cabinets. The shiny side of the films was exposed to the atmosphere at the lowest $\mathrm{RH}\left(53 \% \mathrm{RH}\right.$ at $\left.25^{\circ} \mathrm{C}\right)$. The cups were weighed using an analytical balance (E02140, Ohaus, USA) $( \pm 0.00001 \mathrm{~g})$ at intervals of 1.5 hours during 24 hours. The weight loss versus time plot slope was divided by the exposed film area in order to calculate the water vapor transmission rate (WVTR):

$$
\text { WVTR }=\frac{\text { slope }}{\text { film area }}
$$

WVP was determined by using (2), where $P_{1}$ is the partial pressure $(\mathrm{kPa})$ inside the cup, $P_{2}$ the water vapor partial pressure $(\mathrm{kPa})$ at the film outer surface in the system, and $L$ the average film thickness $(\mathrm{mm})$ :

$$
\mathrm{WVP}=\left(\frac{\mathrm{WVTR}}{P_{2}-P_{1}}\right) L .
$$

2.5. Statistical Analysis. The statistical analysis of the data was performed trough an Analysis of Variance (ANOVA). Tukey test was used for analysis of media, using a $0.95 \%$ confidence level. Statistical analysis was realized using the computational software Minitab (version 14.0).

\section{Results and Discussion}

3.1. Elaboration of Chitosan-Based Films. Chitosan-based films were elaborated incorporating clove (Eugenia caryophyllata) essential oil and clove functional extract, as reported by Hernández-Ochoa et al. [15]. The results obtained in the elaboration of the films are shown in Figure 1, where it can be observed that the films had the following general characteristics: minimum porosity, being transparent and elastic, and having no fractures.

The films that contained clove extract and functional extract of clove presented an opaque color and a strong clove odor; chitosan films with no addition of essential oil and functional extracts had an acetic acid odor. Interactions
TABLE 1: Maximum chitosan film's punction and extensibility force with essential oils and functional extract (added esters $\mathrm{E}_{6}, \mathrm{E}_{7}$ ) of clove.

\begin{tabular}{lcc}
\hline Short of film & $\begin{array}{c}\text { Extensibility } \\
(\mathrm{N})\end{array}$ & $\begin{array}{c}\text { Punction }^{2} \\
(\mathrm{~N})\end{array}$ \\
\hline Chitosan films & $23.63 \pm 0.43^{\mathrm{a}}$ & $3.14 \pm 0.03^{\mathrm{a}}$ \\
Chitosan + essential oil & $24.38 \pm 3.38^{\mathrm{a}}$ & $5.87 \pm 0.31^{\mathrm{b}}$ \\
Chitosan + functional extract $\left(\mathrm{E}_{6}\right)$ & $34.71 \pm 1.58^{\mathrm{b}}$ & $7.18 \pm 0.16^{\mathrm{c}}$ \\
Chitosan + functional extract $\left(\mathrm{E}_{7}\right)$ & $44.05 \pm 3.70^{\mathrm{c}}$ & $9.34 \pm 0.55^{\mathrm{d}}$ \\
\hline
\end{tabular}

Note. ${ }^{1}$ An average of 5 measurements in every film, ${ }^{2}$ an average of 15 measurements in every film. Tukey testing: the averages with the same letter do not significantly differ and the averages with different letter show significant differences $(p<0.05)$. Fatty acids ethyl esters used in this study were ethyl caproate $\left(\mathrm{E}_{6}\right)$ and ethyl heptanoate $\left(\mathrm{E}_{7}\right)$.

between chitosan and different essential oils and esters can involve the nitrogen residues of the primary aliphatic amine present in chitosan, which gives typical reactions of these functional groups, for instance, $\mathrm{N}$-acylation and the Schiff bases formation. On the other hand, chitosan free amino groups also have an association to hydrogen bonds [3]. As expected esters $\mathrm{E}_{6}$ and $\mathrm{E}_{7}$ reacted with transesterification reaction involving the ester carbonyl group $(\mathrm{C}=\mathrm{O})$, the amines groups (NH2), and hydroxyls $(\mathrm{OH})$ functional groups, getting amides and ester bonds as functionalizing agents. It can be considered that the esters may participate as acceptors in the hydrogen bonds, but they cannot participate as donors in this type of bonds.

3.2. Tensile Properties. Considering the observed visual differences, tensile analyses were done (punction and extensibility) to determine the influence of the addition of essential oils and functional extracts into the chitosan films. Based on punction and extensibility $(p<0.01)$ tests results (Table 1 ) showed significant differences among the films.

The films made with esters $\mathrm{E}_{6}, \mathrm{E}_{7}$ had highest levels of extensibility. Compared with the control and chitosanessential oil clove, films made with esters $\mathrm{E}_{6}, \mathrm{E}_{7}$ had a larger stretching capacity but there was only a few increments of resistance in the punction test by resisting just $5 \%$ more than the strength applied for tearing up of the untreated chitosan film. Low values of chitosan films in both tests are in agreement with previous reports since chitosan films are rigid and fragile. Synthetic polymers such as LDPE (lowdensity polyethylene) and HDPE (high-density polyethylene) show high elongation values but similar traction resistance to that of biopolymer films, such as chitosan [19]. According to Lara-Sagahon et al. [10] the molecular measurement, configuration, and the polar group total in plasticizers and fatty acids as well as their compatibility with the chitosan chains are responsible for the modification of the mechanical properties, as the results obtained in this study. It is also observed that chitosan films had low values for strain stress compared to the polyethylene film; this agrees with the literature, which refers that chitosan films are rigid and brittle, since they present low values for elastic modulus, high strength, and low strain to breaking [20]. 


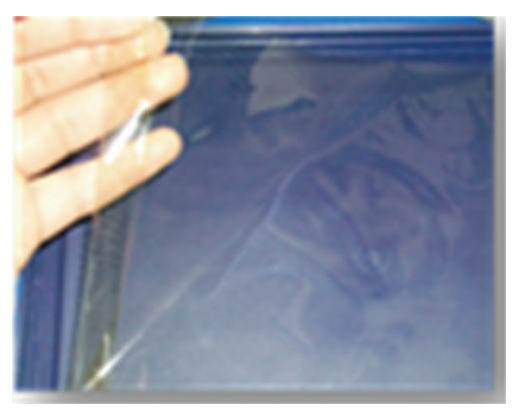

Chitosan film

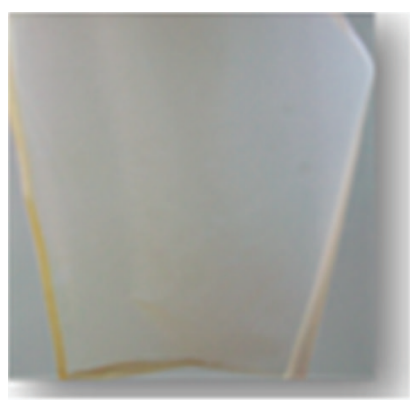

Chitosan + essential oils Clove (Eugenia caryophyllata)

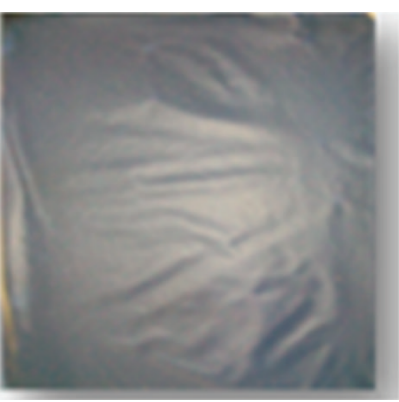

Chitosan + functional extract of clove

FIGURE 1: A typical image of a chitosan-based films including spices of essential oils and functional extract of clove.

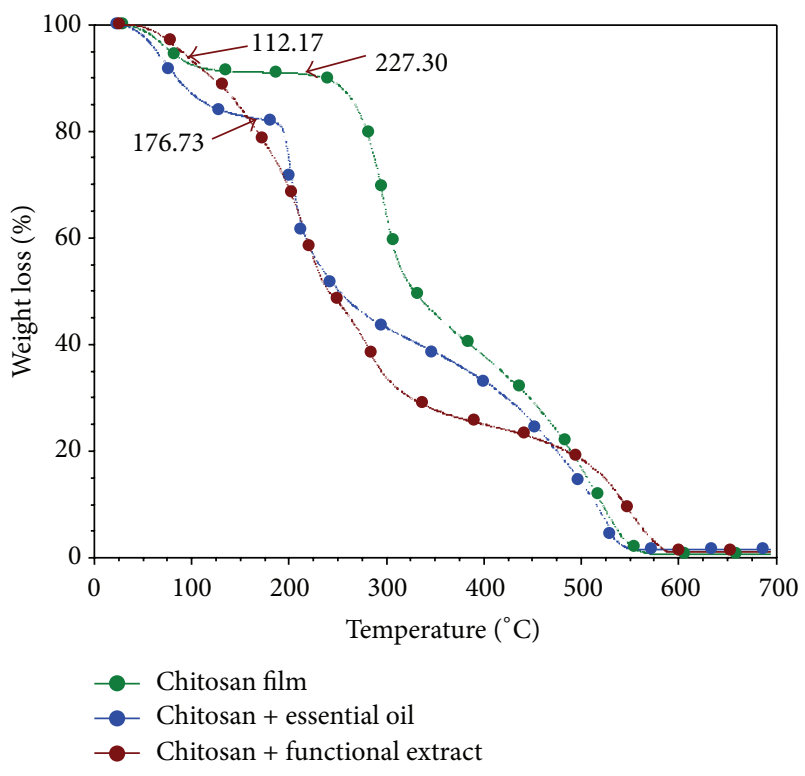

FIGURE 2: TGA curves for chitosan-based films and chitosan film plus the essential oil of clove. Universal V4.3A TA Instruments.

3.3. Thermogravimetric Analysis. The Tga value for the chitosan and chitosan film plus the clove essential oil and pure chitosan were determined $112.17^{\circ} \mathrm{C}, 176.73^{\circ} \mathrm{C}$, and $227.30^{\circ} \mathrm{C}$, respectively. For the chitosan film with clove extract, it was not possible to determine (Figure 2). The differences presented in the Tga values are caused by the concentration of the essential oil and the functional extract present in the sample; the lower concentration of these compounds shows a lower Tga value. These Tga values indicate at what temperature the material undergoes degradation and serves to control the film manipulation and elaboration. The changes in Tga might be related to chitosan hydrolysis in the solvents and the formation of a network involving hydrogen bonds with its amine groups. Increasing the chitosan concentration increased the strength of this network as supported in the report from El-Hefian et al. [21]. Also Martins et al. [22] illustrated that weight loss at $200^{\circ} \mathrm{C}$ related to the chemical absorption of water by hydrogen bonds and elimination of $\mathrm{NH}_{3}$. Santos et al. [23] observed that the temperature of a maximum speed of decomposition for purified chitosan lowered. It is evinced that there is a relation between the degree of acetylation and thermal stability.

3.4. Surface Morphological Analysis by Atomic Force Microscopy. Through atomic force microscopy, the surface of chitosan-based antimicrobial films and the chitosan films incorporating functional extracts was observed to determine their morphology, phase arrangement, and porosity. Figure 3 shows the images obtained in the Atomic Force Microscope. It can be observed that, in general, the films prepared do not present a transversal porosity. The surface of the film containing essential oil of clove (Figure 3(b)) was covered with small pores and seemed to be spongelike. It is postulated that the loose structure observed in these films may be caused by the essential oil components disrupting the ordered structure of the chitosan polymers. The same similar results were obtained by Hosseini et al. [24]. The chitosan-based film incorporating functional extract (Figure 3(c)) shows smooth zones, possibly generated by the incorporation of the extract, which may also suppose the penetration of glycerol which is part of the formulation, thus forming more homogeneous zones. Also, bigger pores were observed in the chitosan film with functional extract of clove in comparison with the films made from only chitosan and without incorporating essential oil.

3.5. Water Vapor Permeability (WVP). The resulting WVP data is presented in Figure 4, where it can be observed that incorporating the functional extract to the formulation of the films had a positive effect on water vapor barrier properties. However, the chitosan films incorporating essential oil of clove showed similar value compared to the just chitosan films. These results mean that the incorporation of functional extract (essential oil of clove + ethyl heptanoate) is more effective to improve the barrier properties of chitosan films, even at the low ratio. This increase may be due to destabilization of chitosan matrix by long chain of functional extract molecules, thus widening the interstitial space in the chitosan matrix and thus allowing for an increased diffusion rate of water molecules through the film. This result is supported by 


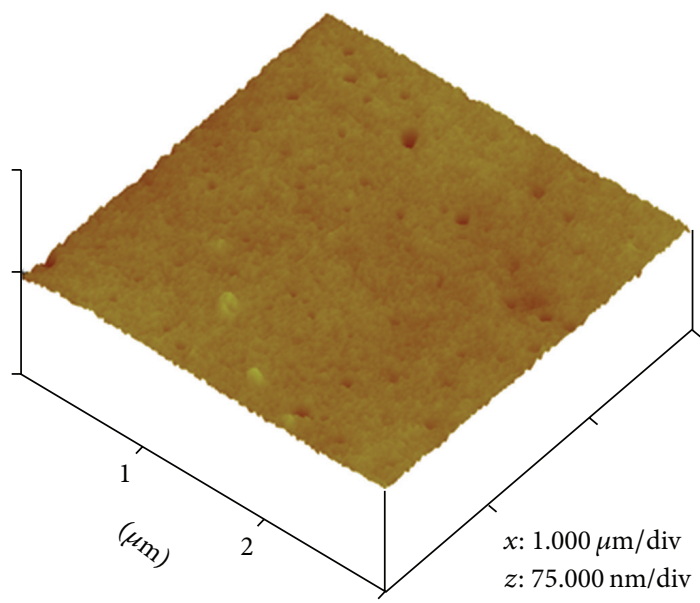

(a)



(b)

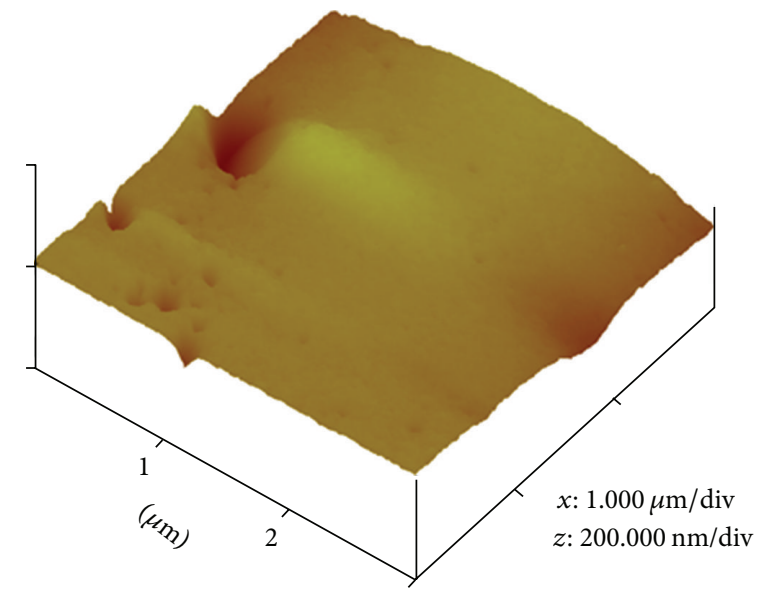

(c)

FIgURE 3: AFM images of the topographic and three-dimensional structures obtained for (a) chitosan films, (b) chitosan film with essential oil of clove, and (c) chitosan film with functional extract of clove.



FIGURE 4: Water vapour permeability of the edible films including essential oils and functional extract of clove. Data are means of three replicates per treatment.

the work of Srinivasa et al. [18], where WVP properties of chitosan lipid blend films were comparable.

\section{Conclusions}

A complete characterization of chitosan-based films blended with essential oil of clove and the functional extract was carried out. The films that contained clove extract and functional oil presented an opaque color and a strong clove odor; chitosan films with no addition of essential oil and functional extracts were clear and with an acetic acid odor. Tensile analyses showed significant differences among films, based on punction and extensibility $(p<0.01)$ determination. The films made with functional extract (esters $\mathrm{E}_{6}$ and $\mathrm{E}_{7}$ ) presented the highest levels of extensibility as compared to the controls and chitosan-essential oil clove. No significant increment in the results of the punction test for the films treated with the esters, those resisted more strength applied before tearing up than the only chitosan films. The results revealed that the addition of functional extract into in chitosan matrix increased the glass transition temperature of the films. The WVP data showed that incorporating the functional extract to the formulation of films has a positive effect on water vapor barrier properties. In general, 
the incorporation of essential oils and functional extract of clove at $20 \%$ in chitosan films gave rise to microstructural changes that were dependent on the different affinity of components. The greatest structural change was induced by essential oil that promoted heterogeneity in pore sizes and shape. These results show the feasibility of using essential oils and functional extracts as natural's plasticizers to obtain flexible films. The films could be even a good candidate to be tested as an active packaging system.

\section{Conflict of Interests}

The authors declare that there is no conflict of interests regarding the publication of this paper.

\section{Acknowledgments}

The authors gratefully acknowledge CIMAV for help in using the Atomic Force Microscope (AFM). Funding for the project was provided by the National Council of Science and Technology of Mexico (CONACYT-Mexico).

\section{References}

[1] M. P. Arrieta, J. López, S. Ferrándiz, and M. A. Peltzer, "Characterization of PLA-limonene blends for food packaging applications," Polymer Testing, vol. 32, no. 4, pp. 760-768, 2013.

[2] N. E. Suyatma, L. Tighzert, A. Copinet, and V. Coma, "Effects of hydrophilic plasticizers on mechanical, thermal, and surface properties of chitosan films," Journal of Agricultural and Food Chemistry, vol. 53, no. 10, pp. 3950-3957, 2005.

[3] A. G. González, A. A. Gardea, and F. C. Navarro, "Nuevas tecnologías de conservación de productos vegetales frescos y cortados," in Uso del Quitosano en Alimentos, pp. 381-397, CIAD, 2005.

[4] Q. Cai, Z. Gu, T. Fu, Y. Liu, H. Song, and F. Li, "Kinetic study of chitosan degradation by an electrochemical process," Polymer Bulletin, vol. 67, no. 4, pp. 571-582, 2011.

[5] S.-I. Park and Y. Zhao, "Incorporation of a high concentration of mineral or vitamin into chitosan-based films," Journal of Agricultural and Food Chemistry, vol. 52, no. 7, pp. 1933-1939, 2004.

[6] K. T. Hwang, S. T. Jung, G. D. Lee, M. S. Chinnan, Y. S. Park, and H. J. Park, "Controlling molecular weight and degree of deacetylation of chitosan by response surface methodology," Journal of Agricultural and Food Chemistry, vol. 50, no. 7, pp. 1876-1882, 2002.

[7] L. Hernández-Ochoa, A. Gonzales-Gonzales, N. GutiérrezMéndez, G. Vilarem, L. N. Muñoz-Castellanos, and A. Quintero-Ramos, "Estudio de la actividad antimicrobiana de películas elaboradas con quitosano a diferentes pesos moleculares," Revista Mexicana de Ingeniería Química, vol. 10, no. 3, pp. 415-424, 2011.

[8] S. Longinos, M. Mendoza, and J. Quezada, "Películas antimicrobianas para carne y productos cárnicos," Mundo Lácteo y Cárnico, vol. 5, pp. 12-17, 2005.

[9] N. Bordenave, S. Grelier, and V. Coma, "Hydrophobization and antimicrobial activity of chitosan and paper-based packaging material," Biomacromolecules, vol. 11, no. 1, pp. 88-96, 2010.
[10] A. V. Lara-Sagahon, S. P. Miranda, G. Cardenas, and D. Lopez, "Comportamiento de películas de quitosano compuesto en un modelo de almacenamiento de aguacate," Revista Mexicana de Ingenieria Química, vol. 47, pp. 331-336, 2003.

[11] K. W. Leong, H.-Q. Mao, V. Chan, and N. Fang, "Interactions of phospholipid bilayer with chitosan: effect of molecular weight and pH," Biomacromolecules, vol. 2, no. 4, pp. 1161-1168, 2001.

[12] I. Leceta, P. Guerrero, I. Ibarburu, M. T. Dueñas, and K. De la Caba, "Characterization and antimicrobial analysis of chitosanbased films," Journal of Food Engineering, vol. 116, no. 4, pp. 889899, 2013.

[13] M. S. Rahman, Handbook of Food Preservation: Packaging As a Preservation Technique, vol. 10, CRC Press, Boca Raton, Fla, USA, 2007.

[14] M. F. Ortuño, Manual práctico de aceites esenciales, aromas y perfumes, Aiyana, Murcia, Spain, 2006.

[15] L. Hernández-Ochoa, C. A. Macías-Castanãeda, G. V. NevárezMoorillón, E. Salas-Munãoz, and F. Sandoval-Salas, "Antimicrobial activity of chitosan-based films including spices' essential oils and functional extracts," CYTA-Journal of Food, vol. 10, no. 2, pp. 85-91, 2012.

[16] B. Ouattar, R. E. Simard, G. Piett, A. Bégin, and R. A. Holley, "Inhibition of surface spoilage bacteria in processed meats by application of antimicrobial films prepared with chitosan," International Journal of Food Microbiology, vol. 62, no. 1-2, pp. 139-148, 2000.

[17] Ph. Lavalle, C. Gergely, F. J. G. Cuisinier et al., "Comparison of the structure of polyelectrolyte multilayer films exhibiting a linear and an exponential growth regime: an in situ atomic force microscopy study," Macromolecules, vol. 35, no. 11, pp. 44584465, 2002.

[18] P. C. Srinivasa, M. N. Ramesh, and R. N. Tharanathan, "Effect of plasticizers and fatty acids on mechanical and permeability characteristics of chitosan films," Food Hydrocolloids, vol. 21, no. 7, pp. 1113-1122, 2007.

[19] P. Sobral, J. Alvarado, N. E. Zaritzky et al., "Films based on biopolymer from conventional and non-conventional sources," in Food Engineering: Integrated Approaches, pp. 193-223, Springer, New York, NY, USA, 2008.

[20] F. C. Soares, F. Yamashita, C. M. O. Müller, and A. T. N. Pires, "Thermoplastic starch/poly(lactic acid) sheets coated with cross-linked chitosan," Polymer Testing, vol. 32, no. 1, pp. 94-98, 2013.

[21] E. A. El-Hefian, M. M. Nasef, and A. A. Yahaya, "The preparation and characterization of chitosan/poly(vinyl alcohol) blended films," Journal of Chemistry, vol. 7, pp. 1212-1219, 2010.

[22] A. F. Martins, A. G. B. Pereira, A. R. Fajardo, A. F. Rubira, and E. C. Muñiz, "Characterization of polyelectrolytes complexes based on N,N,N-trimethyl chitosan/heparin prepared at different pH conditions," Carbohydrate Polymers, vol. 86, no. 3, pp. 1266-1272, 2011.

[23] C. Santos, P. Seabra, B. Veleirinho, I. Delgadillo, and J. A. Lópes da Silva, "Acetylation and molecular mass effects on barrier and mechanical properties of shortfin squid chitosan membranes," European Polymer Journal, vol. 42, no. 12, pp. 3277-3285, 2006.

[24] M. H. Hosseini, S. H. Razavi, and M. A. Mousavi, "Antimicrobial, physical and mechanical properties of chitosan-based films incorporated with thyme, clove and cinnamon essential oils," Journal of Food Processing and Preservation, vol. 33, no. 6, pp. 727-743, 2009. 

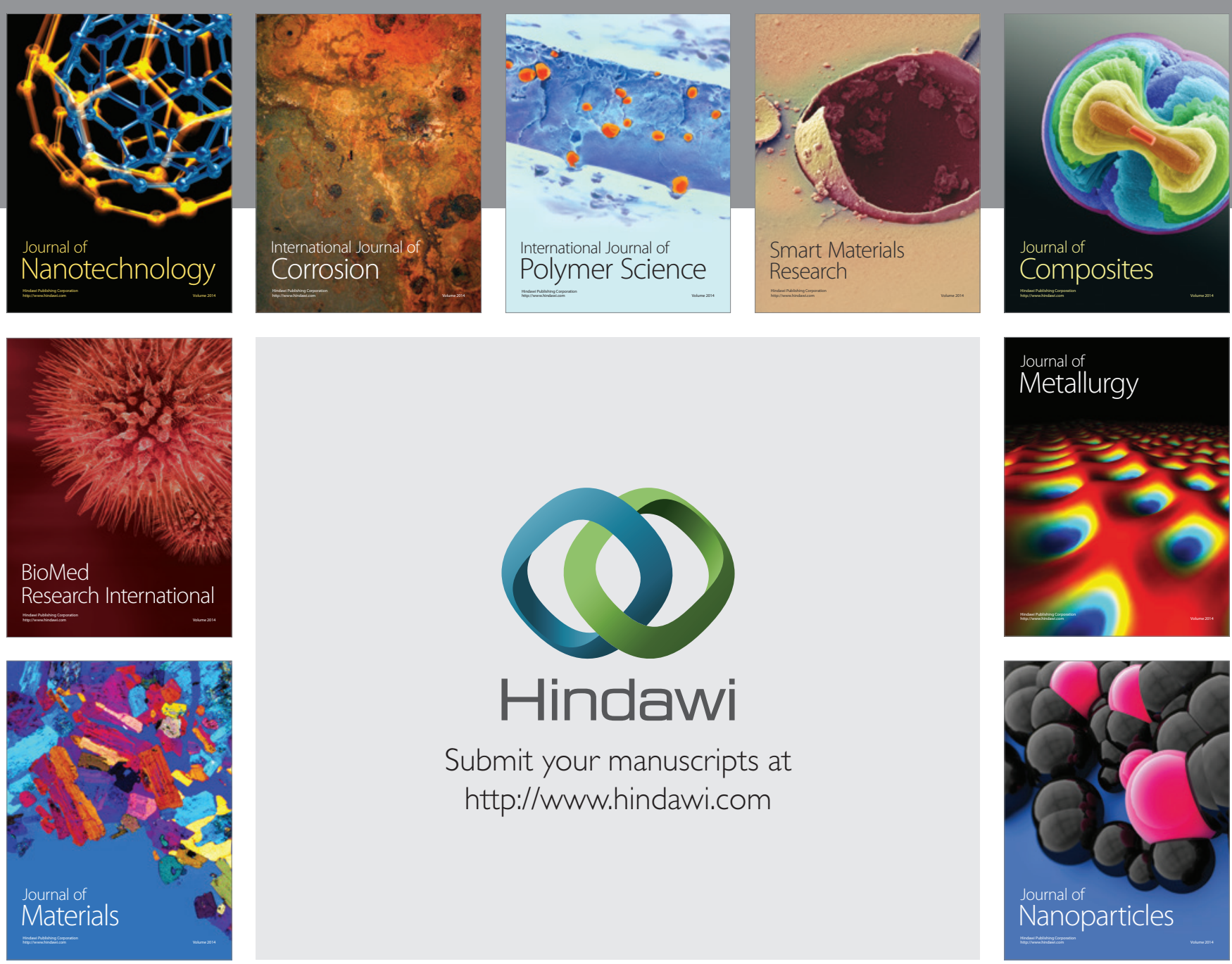

Submit your manuscripts at http://www.hindawi.com
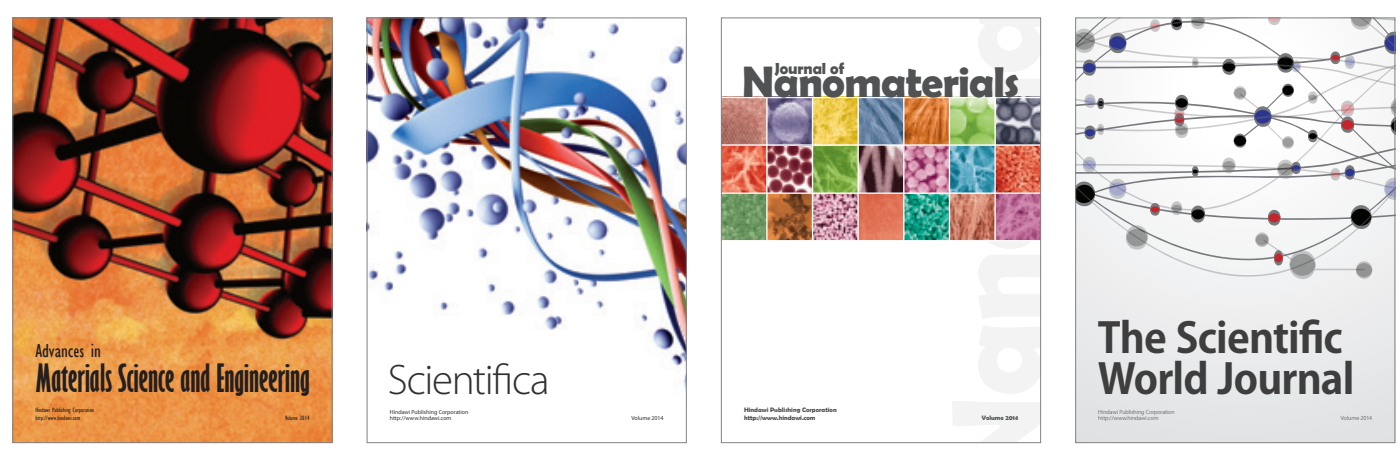

\section{The Scientific World Journal}
